\title{
The public policy approach to injury prevention
}

Despite widespread application of the public health approach to injury prevention, its facilitation of the translation of injury research to practice is limited. This paper describes a public policy approach to injury prevention, derived from Kingdon's streams approach, ${ }^{1}$ which may circumvent the research-to-practice block, specifically for use by practitioners. The central premise of the proposed public policy approach is that policy action is a consequence of windows of opportunity created by the convergence of three streams: (1) problem recognition; (2) development of injury prevention policy; and (3) political will.

The role of the injury prevention practitioner is to encourage a convergence of these elements, and thus maximise the opportunity provided to galvanise policy action. Effective injury prevention relies on creating windows of opportunity and focusing resources on achieving prolonged engagement from all aspects of society. It is not intended that the public policy approach replace the existing public health model, which remains a critical paradigm within which researchers from all disciplines can develop the evidence base for practice. Rather, the role of the public policy approach to injury prevention is to facilitate the implementation of effective countermeasures.

The gap between available research evidence and effective implementation of this research by practitioners (the research-to-practice block) is an important issue that remains to be adequately addressed within the field of injury prevention. ${ }^{2-4}$ The issue is complicated by the fact that many people would consider themselves both researchers and practitioners, and there are many who do injury prevention but may not explicitly identify themselves as injury prevention practitioners. ${ }^{5}$ In this paper we use the term 'practitioner' to refer to any person or body with a role in injury prevention. The purpose of the paper is to explain the basis for the research-to-practice block inherent within the public health approach, and to propose an additional model derived from public policy, specifically for use by practitioners, to facilitate implementation practice.

\section{THE PUBLIC HEALTH APPROACH TO INJURY PREVENTION}

The public health approach to injury prevention is usually described in four stages: (1) defining the problem; (2) identifying causes; (3) developing and testing interventions; and (4) implementing prevention programmes (figure 1). ${ }^{6}$ This is an ordered process that begins with the delineation of the nature and extent of the injury problem through the systematic collection of information about its magnitude, scope, characteristics and consequences. The process then involves a determination of the risk and protective factors that can be modified through intervention. Countermeasures, and strategies for implementing the countermeasures, are then generated to address the modifiable factors. The efficacy of both the countermeasures and strategies are quantified, and effective interventions are then scaled up into programmes for implementation and dissemination at a population level. ${ }^{6}$

The public health approach is well developed in terms of injury surveillance, risk factor identification, and quantifying the efficacy of countermeasures. However, it is underdeveloped in its characterisation of the means by which research evidence is implemented to achieve improved outcomes at the population level. ${ }^{2} 7-10$

The first three stages of the public health approach to injury prevention follow an epidemiological method of scientific enquiry. The fourth stage also relies on scientific enquiry, which is not limited to epidemiology, to determine methods of implementation and intervention effectiveness. This is derived from gaining an understanding of societal values and decision-making processes within government and non-government (both not-for-profit and for profit) organisations. To achieve this, injury prevention practice necessarily takes place in the public domain. The public health approach thus entails a 'research-to-practice' shift that occurs between the third and fourth stages (figure 1). The term 'translation', used to describe the process of moving ideas from the research paradigm into the public domain, reflects the extent of this shift in perspective.

\section{OVERCOMING THE RESEARCH-TO- PRACTICE BLOCK}

Recent work reported in the scientific literature has argued that improved translation from research to practice can be achieved within the current public health approach by improving communication across the researcher-practitioner divide using collaborative forums, knowledge brokers and interactive exchanges. ${ }^{4}$ 11-13 The improved communication would be based on a more overt acknowledgement of the systems and processes involved in translating efficacious interventions into widespread use, ${ }^{6}{ }^{14-16}$ and a recognition of the importance of selecting the most appropriate countermeasures for the implementation context. ${ }^{17}$ Improved communication would encourage the development of the leadership, infrastructure and capacity to facilitate the uptake of evidence-based interventions. ${ }^{3} 5$ 18-20

A critical feature of the research-topractice block is the directional nature of the way the problem has been characterised. The literature, written from the perspective of researchers, ${ }^{21}$ characterises scientific knowledge as something that is generated then 'pushed' through a portal into the world where this new knowledge is 'scaled up' then implemented by practitioners. An alternative to this research centred approach ${ }^{22}$ is a policy opportunity approach $^{22}$ developed from the

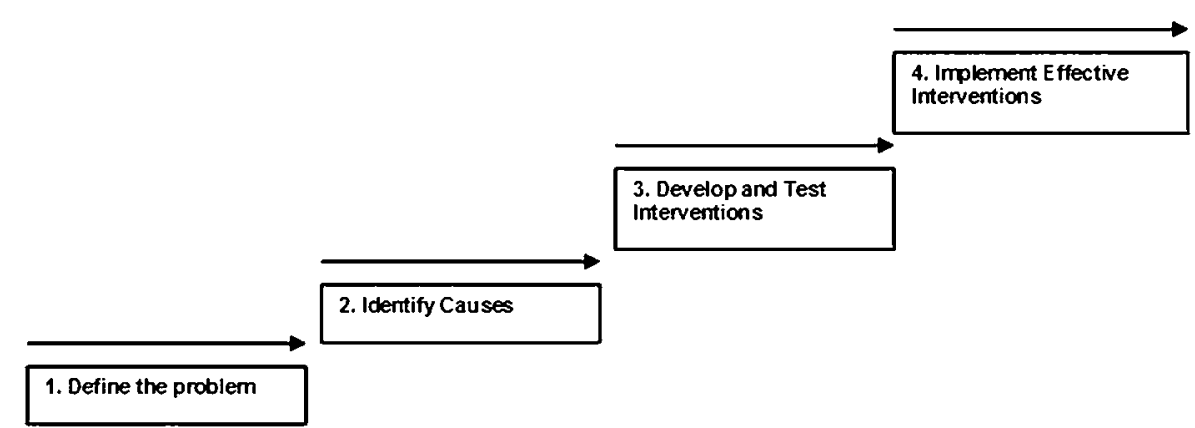

Source: Sleet. Hopkins and Olson, 2003

Figure 1 Public health approach to injury prevention. Source: Sleet et al. ${ }^{6}$ 
perspective of practitioners. This is characterised as knowledge being 'pulled' to populate the components of the public health solution on a needs-only basis

In contradistinction to the research centred 'push' prescribed by the public health approach, we propose a public policy approach, based on Kingdon's streams theory, for use by injury prevention practitioners. The proposed public policy approach 'designs out' the researchto-practice gap by conceptualising the entire prevention process within the public domain. It explains the process by which practitioners 'pull' information from a variety of sources, including epidemiological research, as required to achieve their goals.

\section{PUBLIC POLICY MODELS}

Policy is the interaction of values, processes and outcomes that define the commitment of resources to support specified actions. ${ }^{23-25}$ Public policy frameworks are increasingly being relied upon by the injury prevention community to identify the facilitators and barriers to intervention uptake. ${ }^{26-29}$ These new contributions to the literature suggest that of the available public policy models, the one that holds the most promise for injury prevention is an incremental model called the streams approach, which focusses on how and why policy issues rise and fall from the government agenda. ${ }^{129}$

Kingdon ${ }^{1}$ argues that the processes by which agenda items and alternatives come into prominence are a major factor that influence the policy agenda. Kingdon ${ }^{1}$ categorises policy change in three major process streams:

1. Recognition that a policy problem exists that needs to be addressed (the problem stream).

2. Development, refinement and vetting of policy proposals purporting to correct the policy problem (the policy stream).

3. The flow of political events through which policy changes are erected (the political stream).

Kingdon ${ }^{1}$ suggests that these streams operate independently and that a particular issue is most likely to rise on to the policy agenda when there is an intersection between the streams, referred to as 'coupling'. When coupling occurs it creates a window of opportunity for policy action. Although coupling is often chaotic and unpredictable, policy entrepreneurs often look for or strategically create windows of opportunity for action, for example, when legislation expires or following crisis events such as a major incident in which there are multiple deaths.

\section{THE PUBLIC POLICY APPROACH TO INJURY PREVENTION}

On the basis of the work of Kingdon, ${ }^{1}$ the proposed public policy approach to injury prevention is shown in figure 2 .

Problem recognition is achieved by characterising the problem of injury in a way that gives it currency in the public domain. $^{20}{ }^{30}$ Problem recognition relies extensively on scientific information from surveillance systems. For this surveillance data to make a meaningful impact on the public consciousness they need to be presented in terms of existing or achievable public priorities. ${ }^{18}$ Historical examples illustrate the important role of individuals $^{31}$ and social institutions ${ }^{32} 33$ with a public presence who have initiated activity by clearly putting the case for prevention.

Injury prevention policy preparation is a multidisciplinary, multisectoral activity and is not simply a matter of listing the known efficacious interventions. ${ }^{34}$ Preparing policy involves the ongoing development of principles that guide activities towards desired ends and the preparation of documents that outline preferences and courses of action taken by social institutions. ${ }^{18} 35$ Policy preparation draws from the full range of sciences including epidemiology, psychology, sociology, economics, psychology and engineering to define the solution in terms that are meaningful to the public. In addition, it is a process that frequently entails competition among various groups to promote their respective ideas and improve their respective situations. ${ }^{35}$ Ideally, it involves continual engagement between all interested parties from the time injury prevention needs are first identified, throughout the research process and often long after research is completed.

Political will requires an understanding of how issues are placed on the political agenda. It is dependent on establishing a constituency and framing the injury prevention problem so that its legitimacy is authorised by that constituency and its representatives. ${ }^{20} 3233$ Critical to this is the identification and development of sustained dynamic relationships with the stakeholders. ${ }^{36}$ Ultimately, political will is achieved through the acceptance of shared responsibility arising from an ongoing robust exchange between individuals and representatives of the social structures that define the systems that affect injury risk.

Under this model, the role of the injury prevention practitioner is to encourage

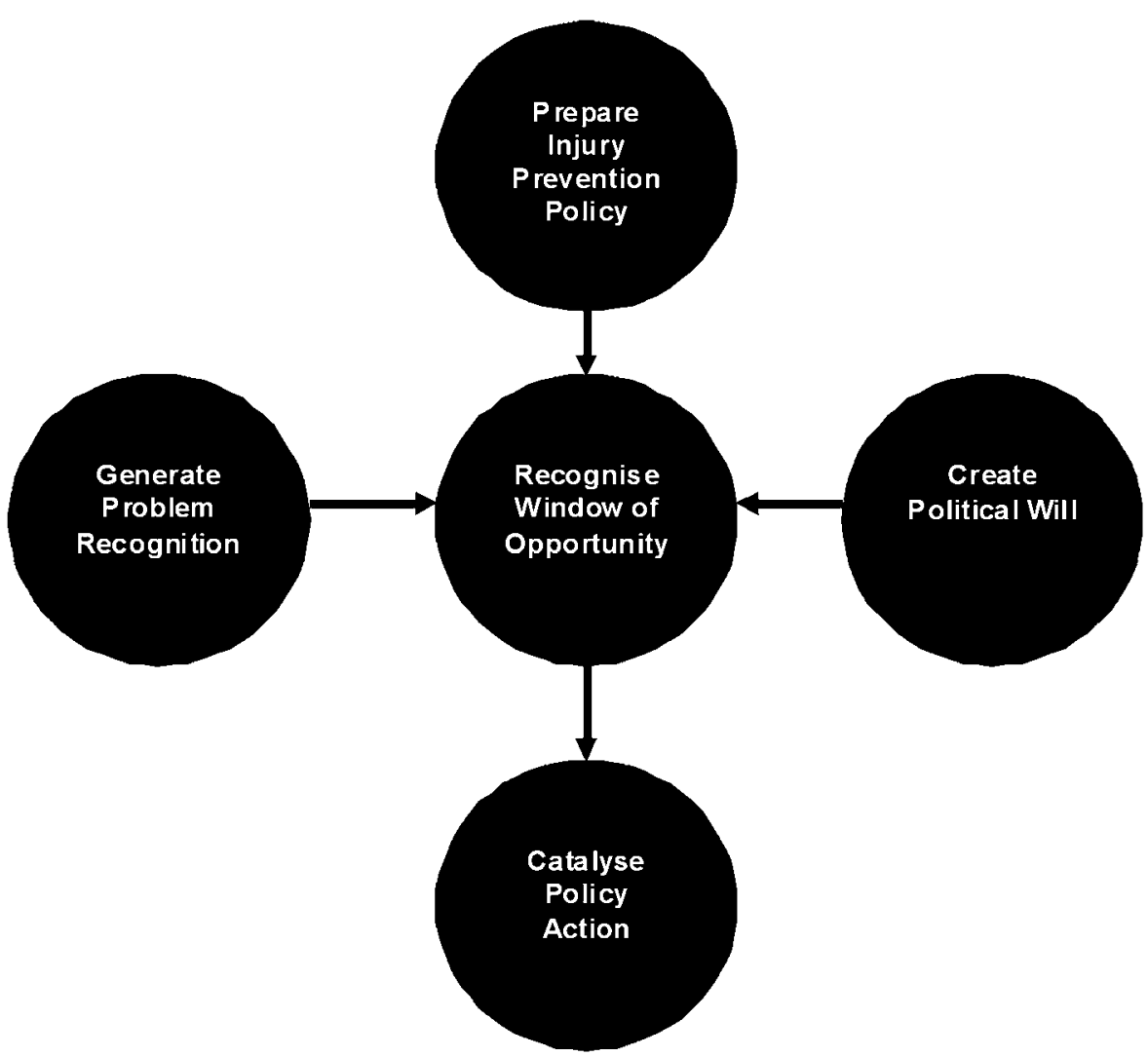

Figure 2 Proposed public policy approach to injury prevention derived from Kingdon. ${ }^{1}$ 
a convergence of these elements to create windows of opportunity and identify when they arise to galvanise policy action. Practitioners work towards sustaining the strength and focus of societal engagement on the highlighted issue in order to produce evidence-based consequences and measurable reductions in the population burden of injury. ${ }^{37}$ The extent to which policy action is effective is ultimately contingent on the intensity of the response. ${ }^{37}$

\section{CONCLUSION}

While researchers should be aware of how their work fits within the proposed public policy model, their own contributions to the bigger picture are better facilitated by working within the paradigms of the current public health models. Science and evidence are the essential prerequisites of good public policy, but scientists provide the information to be used by practitioners rather than an approach for practitioners to follow. Under the research centred approach ${ }^{22}$ the research-to-practice block occurs because the process has its early manifestations in the research domain and it needs to move into the public domain to have effect.

The policy opportunity approach ${ }^{22}$ is better adapted to the public role practitioners play in drawing on existing evidence to activate prevention activity. In the proposed public policy approach to injury prevention, the entire process is born through engagement and consultation and remains in the public domain throughout.

Improving the uptake of research to practice is not a matter of an additional elaboration of the means for facilitating a shift between stages three and four of the public health model. It requires an additional model, described from the practitioner's perspective, to be used in association with the existing models followed by researchers. We suggest that by adopting the public policy approach to injury prevention practitioners will be able to overcome the research-to-practice block successfully, actualise the underused potential of current knowledge, and achieve substantial reductions in the population burden of injury.

Acknowledgements The authors wish to thank Lisa Brodie for advice on this paper and comments on manuscripts.

\section{Lyndal Bugeja, ${ }^{1}$ Roderick J McClure, ${ }^{1}$ Joan Ozanne-Smith, ${ }^{2}$ Joseph E lbrahim ${ }^{3}$}

${ }^{1}$ Accident Research Centre, Monash University, Victoria, Australia; ${ }^{2}$ Prevention Research Unit, Department of Forensic Medicine, Monash University, Victoria,
Australia; ${ }^{3}$ Department of Forensic Medicine, Monash University, Victoria, Australia

Correspondence to Dr Lyndal Bugeja, Accident Research Centre, Building 70, Monash University, Clayton, Victoria 3800, Australia:

lyndal.bugeja@monash.edu

Funding An Australian postgraduate award supported LB for her PhD candidature.

\section{Competing interests None.}

Contributors All authors contributed to the conception and writing of the paper.

Provenance and peer review Not commissioned; externally peer reviewed.

Accepted 1 December 2010

Injury Prevention 2011:17:63-65.

doi:10.1136/ip.2010.030619

\section{REFERENCES}

1. Kingdon JW. Agendas, alternatives and public policies. New York: Longman, 1984:71-89.

2. Mallonee SC, Fowler C, Istre GR. Bridging the gap between research and practice: a continuing challenge. Inj Prev 2006;12:357-9.

3. McClure RJ, Davis E, Yorkston E, et al. Special issues in injury prevention research: developing the science of program implementation. Injury 2010;(41 Suppl 1):S16-19.

4. Peek-Asa C, Casteel CH. Documenting the need for translational research: an example from workplace violence and prevention. Inj Prev 2010;16:50-2.

5. Brownson RC, Hartge P, Samet JM, et al. From epidemiology to policy: toward more effective practice. Ann Epidemiol 2010;20:409-11.

6. Sleet DA, Hopkins KN, Olson SJ. From discovery to delivery: injury prevention at CDC. Health Promot Pract 2003;4:98-102.

7. Smith GS. Public health approaches to occupational injury prevention: do they work? Inj Prev 2001;(7 Suppl 1):i3-10.

8. Pless IB. Bridging from research to practice. Inj Prev 2004;10:1-2.

9. Brussoni ME, Towner E, Hayes M. Evidence into practice: combining the art and science on injury prevention. Inj Prev 2006;12:373-7.

10. Hyder AA, Bloom G, Leach $\mathrm{M}$, et al. Future health systems: innovations for equity. exploring health systems research and its influence on policy processes in low income countries. BMC Public Health 2007; 7:309.

11. Stout NA. The public health approach to occupational injury research: from surveillance to prevention. Saf Sci 2008;46:230-3.

12. Ogilvie D, Craig $P$, Griffin $S$, et al. A translational framework for public health research. BMC Public Health 2009;9:116.

13. Pollack KM, Samuels A, Frattaroli S, et al. The translation imperative: moving research into policy. Inj Prev 2010;16:141-2.

14. Sogolow E, Sleet DA, Saul J. Dissemination, implementation, and widespread use of injury prevention interventions. In: Doll SL, Bonzo S, Sleet DA, et al, eds. Handbook of injury and violence prevention. New York: Springer, 2007:493-510.

15. Wandersman A, Duffy J, Flaspohler P, et al. Bridging the gap between prevention research and practice: the interactive systems framework for dissemination and implementation. Am J Community Psychol 2008;41:171-81.

16. Lett R, Kobusingye 0, Sethi D. A unified framework for injury control: the public health approach and Haddon's matrix combined. Inj Control Saf Promot 2002;9:199-205.
17. Runyan CW. Using the Haddon matrix: introducing the third dimension. Inj Prev 1998;4:302-7.

18. Cohen L, Swift S. The spectrum of prevention: developing a comprehensive approach to injury prevention. Inj Prev 1999:5:203-7.

19. Wolff T. A practitioner's guide to successful coalitions. Am J Community Psychol 2001;29:173-91.

20. Wallack L, Dorfman L. Media advocacy: a strategy for advancing policy and promoting health. Health Educ 0 1996;23:293-317.

21. Mercer SL, Sleet DA, Elder RW, et al. Translating evidence into policy: lessons learned from the case of lowering the legal blood alcohol limit for drivers. Ann Epidemiol 2010;20:412-20

22. Bowen $\mathbf{S}$, Hyde J. Getting research into our policy: lots of ideas but how do we make it happen? Insights from the policy experience. Australasian Epidemiologist 2008;15:10-14.

23. Dalton T, Draper M, Weeks W, et al. Making social policy in Australia: an introduction. St Leonards: Allen and Unwin, 1996:3-22.

24. Colebatch H. Policy. Buckingham: Open University Press, 2002:1-6.

25. Graycar A, Jamrozik A. How Australians live: social policy in theory and practice. 2nd edn. Melbourne: Macmillian, 1993:5-10.

26. Guilbrandsson K. Child health promotion: analyses of activities and policy processes in 25 Swedish municipalities. Stockholm: Karolinska Institutet, 2005:1-124.

27. Poulos RG, Zwi AB, Lord SR. Towards enhancing national capacity for evidence informed policy and practice in falls management: a role for a "Translation Task Group"? Aust New Zealand Health Policy 2007; 4:1-7.

28. Barringer $\mathbf{P}$, Studdert D, Kachalia A, et al. Administrative compensation of medical injuries: a hardy perennial blooms again. J Health Polit Policy Law 2008;33:725-60.

29. Poulos R, Donaldson A, Finch C. Towards evidenceinformed sports safety policy for New South Wales, Australia: assessing the readiness of the sector. Inj Prev 2010;16:127-31.

30. Pitt R, Spinks D. Advocacy. In: McClure RJ, Stevenson M, McEvoy S, eds. The scientific basis of injury prevention and control. Melbourne: IP Communications, 2004:303-17.

31. Marine Safety Victoria. Regulatory impact statement: marine (personal flotation devices and other safety equipment) regulations 2005. Melbourne: Department of Infrastructure, 2005.

32. Cameron MH, Haworth N, Oxley J, et al. Evaluation of Transport Accident Commission road safety advertising. Melbourne: Monash University Accident Research Centre, 1993

33. Elder RW, Shults RA, Sleet DA, et al; Task Force on Community Preventive Services. Effectiveness of mass media campaigns for reducing drinking and driving and alcohol-involved crashes: a systematic review. Am J Prev Med 2004;27:57-65.

34. National Injury Prevention Advisory Council. Directions in injury prevention report 2: Injury prevention interventions - good buys for the next decade. Canberra: Commonwealth Department of Health and Aged Care, 1999.

35. Considine M. Public policy: a critical approach. Melbourne: Macmillian Education Australia, 1994.

36. Conway GA, Lincoln GM, Husberg BJ, et al. Alaska's model program for surveillance and prevention of occupational injury deaths. Public Health Rep 1999;114:550-8.

37. McClure RJ, Hughes K, Ren C, et al. The population approach to falls injury prevention in older people: findings of a two community trial. BMC Public Health 2010;10:79 


\section{The public policy approach to injury prevention}

Lyndal Bugeja, Roderick J McClure, Joan Ozanne-Smith, et al.

Inj Prev 2011 17: 63-65

doi: 10.1136/ip.2010.030619

Updated information and services can be found at:

http://injuryprevention.bmj.com/content/17/1/63.full.html

\begin{tabular}{cl}
\hline These include: \\
References & $\begin{array}{l}\text { This article cites } 24 \text { articles, } 10 \text { of which can be accessed free at: } \\
\text { http://injuryprevention.bmj.com/content/17/1/63.full.html\#ref-list-1 } \\
\text { Article cited in: } \\
\text { http://injuryprevention.bmj.com/content/17/1/63.full.html\#related-urls } \\
\text { Receive free email alerts when new articles cite this article. Sign up in } \\
\text { service } \\
\text { the box at the top right corner of the online article. }\end{array}$ \\
\hline
\end{tabular}

Notes

To request permissions go to:

http://group.bmj.com/group/rights-licensing/permissions

To order reprints go to:

http://journals.bmj.com/cgi/reprintform

To subscribe to BMJ go to:

http://group.bmj.com/subscribe/ 